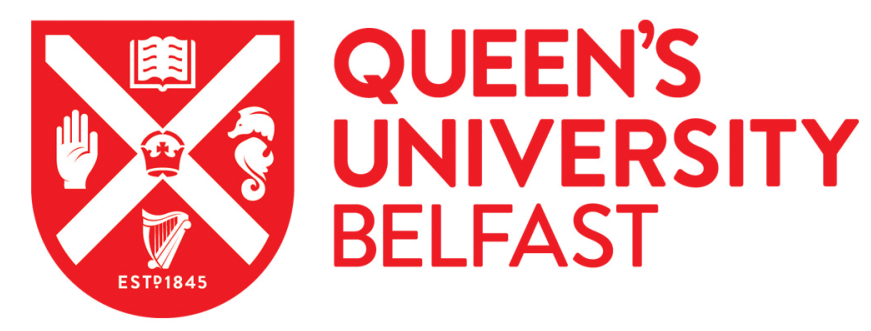

\title{
The Deployment of Low Carbon Technologies in Modern Distribution Networks
}

Mohamed, A. A. R., Morrow, D. J., \& Best, R. (2019). The Deployment of Low Carbon Technologies in Modern Distribution Networks. In 2019 IEEE PES Innovative Smart Grid Technologies Europe (ISGT-Europe):

Proceedings Institute of Electrical and Electronics Engineers Inc.. https://ieeexplore.ieee.org/document/8905643

Published in:

2019 IEEE PES Innovative Smart Grid Technologies Europe (ISGT-Europe): Proceedings

\section{Document Version:}

Peer reviewed version

Queen's University Belfast - Research Portal:

Link to publication record in Queen's University Belfast Research Portal

Publisher rights

(c) 2019 IEEE.

This work is made available online in accordance with the publisher's policies. Please refer to any applicable terms of use of the publisher.

\section{General rights}

Copyright for the publications made accessible via the Queen's University Belfast Research Portal is retained by the author(s) and / or other copyright owners and it is a condition of accessing these publications that users recognise and abide by the legal requirements associated with these rights.

Take down policy

The Research Portal is Queen's institutional repository that provides access to Queen's research output. Every effort has been made to ensure that content in the Research Portal does not infringe any person's rights, or applicable UK laws. If you discover content in the Research Portal that you believe breaches copyright or violates any law, please contact openaccess@qub.ac.uk. 


\section{The Deployment of Low Carbon Technologies in Modern Distribution Networks}

\author{
Ahmed A. Raouf Mohamed \\ Queen's University Belfast \\ Belfast, UK \\ amohamed06@qub.ac.uk
}

\author{
D. John Morrow \\ Queen's University Belfast \\ Belfast, UK \\ dj.morrow@qub.ac.uk
}

\author{
Robert Best \\ Queen's University Belfast \\ Belfast, UK \\ r.best@qub.ac.uk
}

\begin{abstract}
Most modern distribution networks are experiencing an energy evolution to satisfy the need of sustainable, secure and clean sources of energy. New technologies are driving this transition, including photovoltaics, energy storage systems and electric vehicles. The integration and deployment of these technologies in the distribution network is having a positive impact on system efficiency. However, their behavior in the power system introduces technical challenges such as reverse power flow, voltage variation and other power quality issues. The integration of these technologies requires careful planning and operation to maintain or improve system stability and reliability. This work reviews the challenges imposed by deploying these low carbon technologies on low voltage systems. The main contributions of this study can be summarized as follows: Firstly, it generally reviews the solution methodologies and power management strategies applied in the distribution network in the presence of low carbon technologies. Secondly, it outlines some important facts and statistics about their deployment. Finally, it discusses the energy evolution of the Northern Ireland network highlighting challenges and solutions and providing recommendations for future research.
\end{abstract}

Index Terms- Battery Energy Storage Systems, Distributed Generation, Distribution Networks, Electric Vehicles, Low Carbon Technologies, Photovoltaics.

\section{INTRODUCTION}

The conventional power system framework, which consists of generation, transmission and distribution, has recently faced many technical and non-technical problems. Technical challenges include supply security, voltage variation, line losses and rapid increase in demand. Environmental and economic problems include fluctuations in fossil fuel prices and emissions which are harmful to human health and the environment. Finding solutions to these problems has drawn a considerable amount of academic and industry research. Many solutions focus on turning the distribution network (DN) from being normal passive into smart active network [1]. These solutions include integrating various types of distributed energy resources and low carbon technologies (LCTs) in the DN.

Different distributed energy resources, presently being installed in the DN, have significant control potential, particularly distributed generation (DG). There are many types of DGs, some of them are based on fossil fuels and others are renewable energy based. Renewable energy DGs (RDGs) have been integrated into the DN due to their economic and environmental benefits. Despite their benefits, RDGs require careful consideration in their operation due to their intermittent power output. This intermittency is primarily caused by fluctuations in wind speed and solar irradiance. In addition, high penetrations of these resources can cause reverse power flow, for which the DN may not have been designed [2].

One important LCT that may radically alter the demand on the DN is the Electric vehicle (EV). The use of these low carbon vehicles has seen a tremendous increase recently, due to their positive environmental and economic footprint. Many vehicle manufacturers have started introducing hybrid electric vehicles, fuel cell vehicles, battery EVs (BEVs) and plug-in hybrid EVs (PHEVs) to the market. From the electrical network point of view, BEVs and PHEVs are only considered as they act as loads on the DN during their charging periods [3]. Despite their advantages, the charging pattern of EVs causes network stresses that lead to negative impacts on the supply quality and security.

Energy storage technology has developed rapidly to be connected to the DN. Energy storage systems (ESS) are very important, especially with the renewable energy applications to store energy in off peak periods and deliver it during peak periods [4]. There are different types of ESS that can be employed in the system based on their operation and internal structure. However, battery energy storage systems (BESS) are considered as they have many benefits in terms of flexibility, practicality, size and price. The use of BESS has increased as consumers want to minimize imported power from the grid, particularly during high tariff times, and network operators want to increase system stability and peak lopping.

Previous literature reviews have focused on the benefits, challenges, economic and technical aspects of integrating these technologies in the DN [5], [6]. This paper extensively focusing on the challenges concerned with the integration of RDGs, EVs and ESS in the DN at the low voltage (LV) level. Photovoltaics (PV) based DGs (PVDGs) are considered in this paper as an important type of RDGs as they can easily be installed at domestic level. Recent research on the integration, management and operation of these technologies is presented. Their deployment in the electricity network of the United Kingdom and their drawbacks are explored. In addition, the problems concerned with Northern Ireland (NI) network due to the high uptake of LCTs are reviewed and the transition of its operators from being distribution network operators (DNO) into distribution system operators (DSO) is highlighted.

This work is part of SPIRE2 (Storage Platform for the Integration of Renewable Energy 2) project, supported by the European Union's INTERREG VA Programme, managed by the Special EU Programmes Body (SEUPB). The views and opinions expressed in this paper do not necessarily reflect those of the European Commission or the SEUPB. 
The structure of this paper is as follows: Section II reviews the deployment of PVDGs; Section III investigates the technical challenges behind the EV; Section IV introduces ESS as a reliable solution; Section V discusses the future of the NI network and Section VI contains the discussion and conclusion.

\section{II.THE DEPLOYMENT OF PVDGs}

PVDGs have gained much attention in the last few years due to several advantages. While PVDGs can be installed as standalone systems, only grid connected systems are considered in this review as they can impose technical challenges to the electrical network. The deployment of grid connected PVDGs has increased significantly in the UK over the last few years, as shown in Fig.1. According to the solar photovoltaics deployment in the UK report, December 2018 [7], the total capacity of solar energy in the UK is $13,082 \mathrm{MW}$ representing $6 \%$ of total electricity generation capacity and denoting $18.126 \%$ of the total renewable share of electricity generation in the UK.

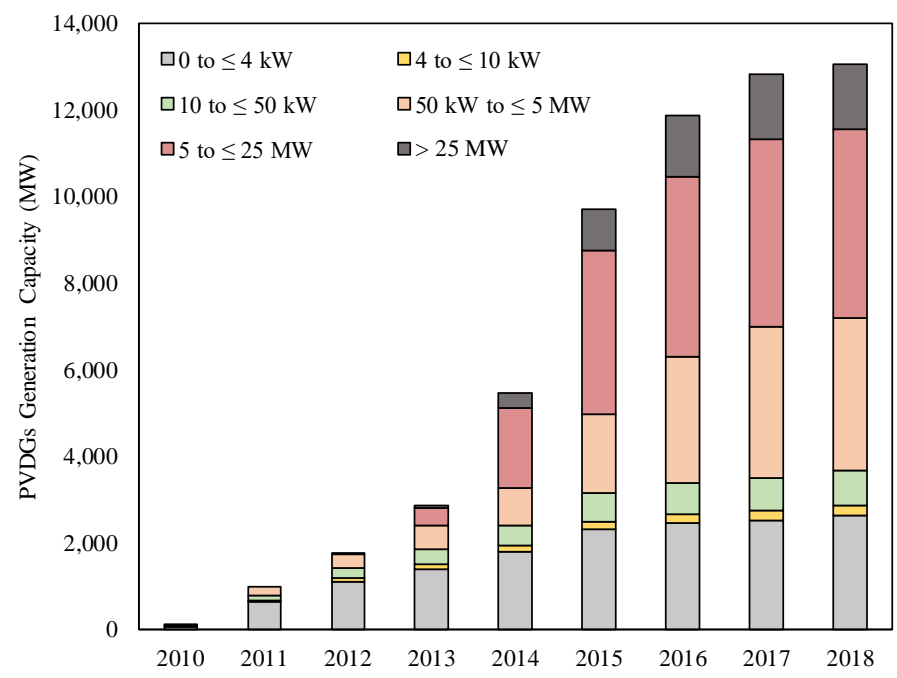

Fig. 1. PVDGs Deployment by Capacity in the UK [7]

The deployment of so much PVDG is causing multiple problems, often resulting from intermittency and reverse power flows. A result of reverse power flow can be the noticeable rise in feeder voltage which adversely affects system stability and power quality. Additionally, power loss, protection issues, and cable ampacity violations [8], are presented as technical challenges for the PVDGs integration. Hence, the integration of significant volumes of these units requires planning and operational considerations to achieve maximized benefits while respecting network constraints.

Diverse studies have proposed various solutions to the problems caused by the PVDGs in the DN. In [9], a potential solution to the allocation and sizing problem is presented using Particle Swarm Optimization considering the impact of reverse power flow. Different reverse power flow scenarios were investigated and simulated. However, the DGs optimal placement can be implemented at the planning phase of new installations and cannot be considered with the existing PVDGs. In [10], a smart transformer design is proposed that optimizes the network during reverse power flow conditions. The transformer employs three power electronics converters with the aim of controlling the voltage profile at the low voltage level. However, while it is effective at mitigating some problems, the power electronic converters greatly increase the harmonics.

Other methodologies focused on developing a power management strategy that could be implemented through controlling the inverters to limit the feed-in power into the grid. PVDG power dispatch is addressed in [11], the objective is to preserve the maximum power output from the PVDGs considering intermittency in the generated power. This is achieved through managing power dispatch and the on-load tap changer (OLTC) at the feeder substation. However, controlling the power dispatch is feasible only for dispatchable PVDGs and not applicable for non-dispatchable PVDGs.

In [12], four different strategies were implemented, these controlled both the PVDG inverter's real and reactive power dispatch, as-well-as the OLTC transformer tap position. The aim was to limit the voltage rise and increase PV penetration in a technical and economically efficient manner. In [13], PVDG active power feed-in is controlled to maintain stable operation under sudden changes in irradiance, while minimizing transmission losses. However, these methodologies require special expensive inverters and not all PVDG owners have installed them, especially at the residential level.

\section{The Techincal Challenges Behind the EV}

The hurried deployment of EVs is due to their availability in the market and the advantages they provide in terms of clean and cost-effective way of transportation. The transition from conventional fuel-based vehicles to low carbon EVs is accelerating all over the world [14]. Many governments have defined a milestone within the next 20 years in which they will ban the sale of conventional vehicles. The UK government has decided to fulfill that zero emissions commitment by 2040 . The Scottish government has set a target of 2032, motivating the UK government to investigate the possibility of alignment with the Scottish government's target and becoming a world leader in this energy evolution [15]. The total number of EVs in the UK has exceeded the 200,000 vehicles by the end of 2018, according to the International Energy Agency (IEA), The Society of Motor Manufacturers and Traders (SMMT) and the UK Office for Low Emission Vehicles. It is expected that the uptake of EVs may exceed the 20 million vehicles by 2030 [2].

EVs can be charged at homes, workplace and public charging points or via charging points provided by aggregator companies. According to recent statistics, May 2019; there are 22,557 (Normal/Fast/Rapid) charging points around the UK [16]. The charging regimes of EVs increase stress on the electrical system as EVs are effectively acting as fixed or variable loads, increasing overall demand. This increase in demand creates challenges for the DNO, with regard to voltage, transformer and cable thermal loadings, line losses and other power quality issues. Hence, the large-scale deployment of EVs requires some regulations and considerations to maintain existing stability and power quality standards.

Different studies have addressed the challenging impact of EVs charging and proposed some approaches to mitigate these impacts. In [17] a charging algorithm is presented that allows EV owners to charge their vehicles in a manner that maintains normal household demand and avoids violating DN constraints. 
The algorithm uses the local voltage to determine the spare capacity in the network for each EV through its charger controllers. The main contribution in this study is that it provides a charge management algorithm that does not require special metering devices or new infrastructure; as it depends only on local measurements recorded by the EVs' chargers.

Another algorithm is proposed in [18], its aim is to optimally control the charging of EVs sequentially to minimize losses. The algorithm determines the available power to charge EVs based on the residential demand and the system capacity. The algorithm requires some data such as each EV's traveling pattern and state of charge to determine the energy needed for each EV. Simulations and case studies recommend using lower charging power for better minimization of losses. However, both algorithms did not consider the electricity time of use tariff, which is an important factor in the modern networks.

Another study proposed a multi-stage strategy that provided a solution to the EVs charging and discharging dispatch [19]. The objective of this strategy is to minimize the charging cost for EV owners while maximizing the revenue of EV aggregator companies. However, this study focused only on the economic aspects and did not consider any technical issues in their strategy. In [20], another decentralized power management algorithm is proposed that provides a good charging service to EV owners, with a reduced cost, without violating the thermal bounds of the substation. The study simulated the algorithm on a low voltage $(\mathrm{LV})$ residential network in the UK.

A Multi-Agent System (MAS) is employed in [21], to solve the scheduling problem of EVs in the UK. The MAS structure consists of two types of agents that aim to minimize the charging prices based on the EV load forecasting model while not surpassing the transformer and feeder operational limits. Though, these studies focused only on mitigating the thermal effect of EV charging on the substation transformer/feeders, they did not consider other important technical issues such as voltage, frequency and power losses.

\section{ESS AS A RELIABLE SOLUTION}

ESS are attractive to network operators and consumers due to their ability to solve different technical issues arising from PVDGs in the DN. The significant drop in BESS prices has encouraged people to add more of these systems, potentially increasing the maximum capacity of PVDGs in the DN. BESS may be used to mitigate some of the technical issues arising from EV deployment. BESS could provide the additional energy required by the network during peak demand. The installations of BESS in the UK have rapidly increased to reach 6,874 MW in 2018 [22]. The installations of BESS can accelerate the transition to the smart DN. However, their integration requires careful planning and management for maximum efficiency.

Determining the optimal placement and sizing of BESS is a crucial issue that must be investigated. BESS allocation is an optimization problem. Different methodologies are presented to solve this problem using conventional and metaheuristic optimization techniques. A comprehensive state-of-the-art review on the BESS allocation and sizing problem is presented in [23]. In [24], a BESS economic power dispatch algorithm is proposed to minimize the average energy price in the DN without using energy pricing forecasting schemes. The proposed algorithm considers the net stored energy value and different operating limits to determine the charging and discharging power dispatch of BESS in grid-connected and islanded modes to achieve energy arbitrage while minimizing the cost of energy. However, this study did not consider the integration of RDGs or EVs in the DN.

Other studies investigated the energy management of BESS in the presence of PVDGs and EVs. In [25], an optimization algorithm is presented to minimize the cost of EVs' charging at charging stations equipped with BESS and PVDGs. The optimization management algorithm performs the optimization on a real time basis, considering the time of use, electricity prices and without the need of forecasted data, PVDG's output power or local demand.

\section{THE Future OF NORTHERN IRELAND NETWORK}

The Northern Ireland (NI) network is operated by Northern Ireland Electricity Networks (NIEN), which is responsible for managing the low voltage customer side including any installed DGs. General information and recorded data at the end of 2018 for NI network are given in Table I [26], [27].

The deployment of LCTs is increasing in NI network, motivating the DNO to propose different regulations to manage this energy evolution. These regulations facilitate the transition into active distribution networks. NIEN allow consumers to participate in the wholesale electricity market by exporting power generated from their PVDGs. Most customer owned PVDGs are typically roof installations in the region of $4 \mathrm{~kW}$ as this attracted the best feed in tariff before January 2016. The feed in tariff program has been updated to add all systems up to $10 \mathrm{~kW}$ [28], encouraging people to add more units, increasing overall penetration in the DN. The installed capacity of PVDGs has reached 368.8 MW in 2018 as shown in Fig.2.

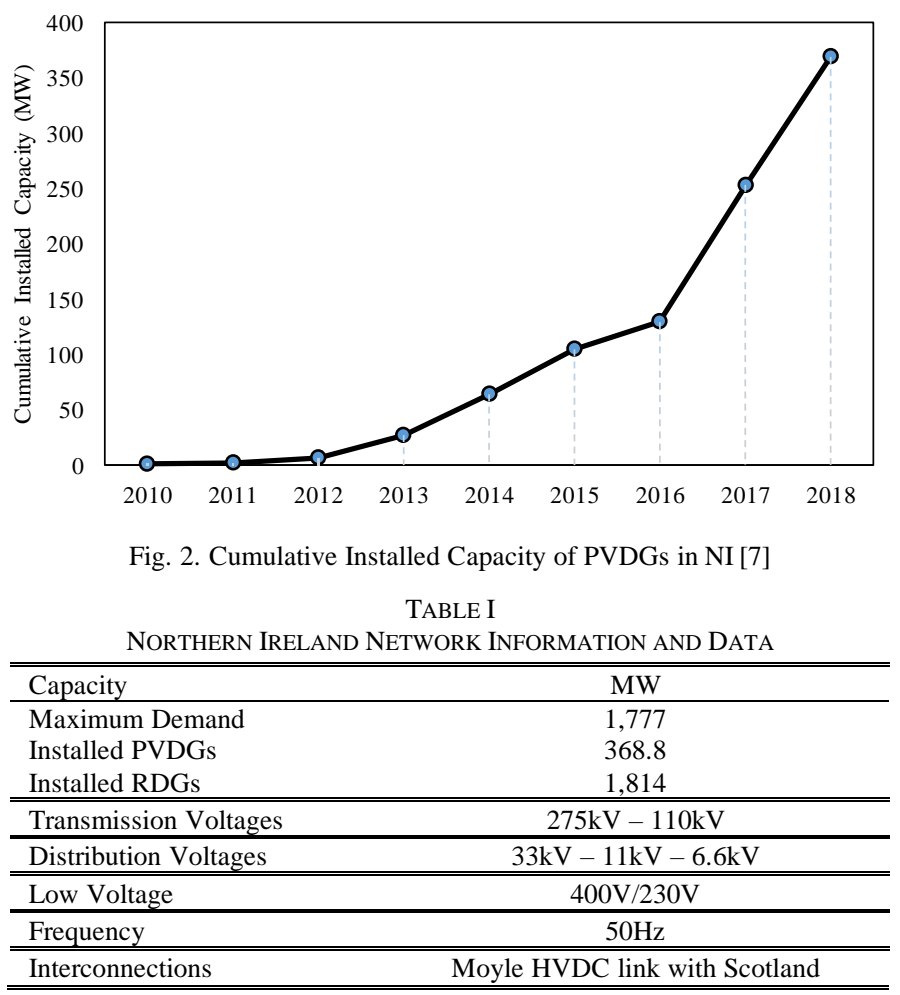


The deployment of EVs in NI is also growing. There are around 2,000 EVs with 486 public charging points in addition to other private charging points [29], [16]. Despite their benefits, their rapid deployment would represent a major increase in total demand. Furthermore, the electrification of heat using electric heat pumps is also increasing significantly, placing an additional burden on the DN.

The anticipated increase in demand needs to be managed to avoid network violations. Reverse power flow, caused by the extra power generated from PVDGs, could also increase network congestion. NIEN are cooperating with other network operators and the Energy Networks Association (ENA) in the open networks project to help drive the transformation of the existed networks to low carbon networks [30]. NIEN are adopting two investment methodologies; conventional reinforcement and smart incremental reinforcement, to manage the network congestion [31].

The conventional reinforcement methodology is based on upgrading the infrastructure such as adding bigger transformers, underground cables and overhead lines. These solutions afford a high level of supply security and durability. However, they require high capital investments. On the other hand, the smart incremental methodologies are based on adopting smart and market-based strategies that actively manage the electrical elements in the system, including LCTs to enhance the operation of the network. Smart solutions can be employed at different levels in the electrical network and can effectively mitigate the stresses on the grid as well as delivering financial savings to the customers and DSO. However, applying smart solutions requires robust research to simulate and validate the right approach to be implemented for operational and cost effectiveness.

Unfortunately, there is a paucity of research focused on the NI network and many technical and economic aspects have not been addressed. In [32], an optimal BESS allocation solution on the customer side of the NI network is presented. In addition, the study investigates the charging of EVs in the presence of RDGs and BESS to achieve energy balance taking into consideration different operation modes including islanded mode. Another study in [33], provides a transient stability analysis for the EVs charging at different points around the NI network. Different scenarios were simulated to provide the necessary requirements for accommodating the anticipated EV fleet in NI by 2020.

Few studies have focused on simulating and studying the PVDGs integration impact on the NI networks. In [34], a load forecasting approach is introduced based on short-term data for NI network in the presence of high penetrations of RDGs. In [35], a performance analysis of grid connected PVDGs in NI networks for long-term basis under practical operating conditions is presented. Other studies investigated the impact of the integration of wind energy into the NI networks [36], [37].

\section{DisCUSSION AND CONCLUSION}

The UK is committed to the delivery of sustainable development goals which motivates the government to decarbonize different industrial sectors such as the power and energy sector [38]. The decarbonization evolution have motivated the UK Office of Gas and Electricity Markets
(Ofgem) to propose the Low Carbon Networks Fund (LCNF) scheme with a budget of $£ 500 \mathrm{~m}$ [39]. The LCNF was conducted through 63 projects by the DNOs in Britain to facilitate the DSO and low carbon economy transitions. The projects focused on the integration of LCTs, BESS and smart metering/monitoring devices as well as applying smart management solutions. The LCNF has created an effective collaboration between the DNOs, industrial and academic partners in developing feasible solutions that can provide the security and quality of supply to the electrical network of the UK.

Research should involve real network models and real problems, to support the DSO transition and energy evolution. NIEN are planning to give the end-users a greater access to the DN by allowing them to participate in the energy flow and trade paradigm. Simultaneously, NIEN are trying to mitigate the challenges of reverse power flow by offering connection standards for customer owned PVDGs which limit the exported power to the grid. On the other hand, a $7 \mathrm{~kW}$ standard charging is recommended for EVs to maintain the system stability in NI networks [33]. However, it is very difficult to control all charging points and such charging limitation will affect consumer satisfaction, as EVs owners would like to charge their vehicles at any time as fast as possible without any charging restrictions.

Integrating BESS has long been seen as a potential solution to some of the network problems to mitigate the network congestion. BESS may be used to reduce network costs and flatten demand profiles. Additionally, BESS can be adopted in power management strategies for different network scenarios to improve the DN performance. In addition, demand side management (DSM) programs have proven to bring great technical and economic values to the DSO and users [40]. Therefore, suitable DSM programs should be developed for industrial and residential consumers. Especially, demand side response programs to encourage consumers to reduce their demand according to time of use signals. These decentralized schemes could provide additional energy to the market and reduce network congestion.

All the reviewed papers on Smart management solutions, in the presence of LCTs, could be applied to and modeled on NI networks. However, applying these solutions requires Smart communication, monitoring and control devices which might not be yet available. BESS and reactive power compensators sizing and sitting methodologies can be considered and applied for all voltage levels in NI network as they do not require any special devices. Nevertheless, conducting relevant studies on NI network is beneficial, e.g. simulating power flow scenarios for various LCTs uptake and scrutinizing the appropriate smart solutions to be executed in further stages that enable cost efficient and secure integration of LCTs.

In conclusion, the aim of this study is to review the deployment of LCTs in the modern DN. Some important statistics, challenges and suggested solutions regarding the deployment of these technologies in the UK are presented. The main contribution of this paper is that it has highlighted and discussed the challenges facing modern networks due to the daily increase in LCTs uptake. The decarbonization evolution by the electricity sector in the UK and NI is the main motivation behind this research, intensively focusing on the NI network as 
a case study, which has not been considered in any previous research. Future research should focus on solving the energy arbitrage problem in the DN in presence of LCTs through proposing the applicable solutions and feasible methodologies to be implemented and embraced by DSO to achieve technical and economic benefits.

\section{REFERENCES}

[1] Liang Chen, Mengmeng Jia, Xiaodong Yuan and Huang Qiang, "Construction and application research of Active Distribution Network Situation Awareness System," 2016 IEEE PES Asia-Pacific Power and Engineering Conference (APPEEC), Xi'an, China, 2016, pp. 863-869.

[2] S. K. Solanki, V. Ramachandran and J. Solanki, "Steady state analysis of high penetration PV on utility distribution feeder," PES T\&D 2012, Orlando, FL, 2012, pp. 1-6.

[3] P. Papadopoulos, S. Skarvelis-Kazakos, I. Grau, L. M. Cipcigan and N. Jenkins, "Electric vehicles' impact on british distribution networks," in IET Electrical Systems in Transportation, vol. 2, no. 3, pp. 91-102, September. 2012.

[4] M. Faisal, M. A. Hannan, P. J. Ker, A. Hussain, M. B. Mansor and F. Blaabjerg, "Review of Energy Storage System Technologies in Microgrid Applications: Issues and Challenges," in IEEE Access, vol. 6, pp. 3514335164, 2018.

[5] S. Parhizi, H. Lotfi, A. Khodaei and S. Bahramirad, "State of the Art in Research on Microgrids: A Review," in IEEE Access, vol. 3, pp. 890-925, 2015.

[6] Allan, G., Eromenko, I., Gilmartin, M., Kockar, I. and McGregor, P., "The economics of distributed energy generation: A literature review". Renewable and Sustainable Energy Reviews, vol 42, pp. 543-556, 2015.

[7] Department for Business, Energy \& Industrial Strategy, "Solar photovoltaics deployment", January 2019. [Online]. Available: https://www.gov.uk/government/statistics/solar-photovoltaicsdeployment

[8] T. Aziz and N. Ketjoy, "PV Penetration Limits in Low Voltage Networks and Voltage Variations," in IEEE Access, vol. 5, pp. 16784-16792, 2017.

[9] K. I. Sgouras, A. S. Bouhouras, P. A. Gkaidatzis, D. I. Doukas and D. P. Labridis, "Impact of reverse power flow on the optimal distributed generation placement problem," in IET Generation, Transmission \& Distribution, vol. 11, no. 18, pp. 4626-4632, 21122017.

[10] G. De Carne, G. Buticchi, Z. Zou and M. Liserre, "Reverse Power Flow Control in a ST-Fed Distribution Grid," in IEEE Transactions on Smart Grid, vol. 9, no. 4, pp. 3811-3819, July. 2018.

[11] J. Li, Z. Xu, J. Zhao and C. Wan, "A Coordinated Dispatch Model for Distribution Network Considering PV Ramp," in IEEE Transactions on Power Systems, vol. 33, no. 1, pp. 1107-1109, Jan. 2018.

[12] T. Stetz, F. Marten and M. Braun, "Improved Low Voltage GridIntegration of Photovoltaic Systems in Germany," in IEEE Transactions on Sustainable Energy, vol. 4, no. 2, pp. 534-542, April 2013.

[13] A. Sangwongwanich, Y. Yang and F. Blaabjerg, "High-Performance Constant Power Generation in Grid-Connected PV Systems," in IEEE Transactions on Power Electronics, vol. 31, no. 3, pp. 1822-1825, March 2016.

[14] Bunsen, T.; Cazzola, P.; Gorner, M.; Paoli, L.; Scheffer, S.; Schuitmaker, R.; Tattini, J.; Teter, J. "Global EV Outlook 2018: Towards Cross-Modal Electrification," International Energy Agency, Paris, France, 2018.

[15] Business, Energy and Industrial Strategy Committee, "Electric vehicles: driving the transition", Fourteenth Report of Session 2017-19, October 2018. [Online] https://publications.parliament.uk/pa/cm201719/cmselect/cmbeis/383/383.pdf

[16] UK's No.1 charging point platform (Zap-Map). "Charging point statistics 2019”, May 2019. [Online]. Available: https://www.zapmap.com/statistics/

[17] Lu Xia, I. Mareels, T. Alpcan, M. Brazil, J. de Hoog and D. A. Thomas, "A distributed electric vehicle charging management algorithm using only local measurements," ISGT 2014, Washington, DC, 2014, pp. 1-5.

[18] R. Sinha, E. R. Moldes, A. Zaidi, P. Mahat, J. R. Pillai and P. Hansen, "An electric vehicle charging management and its impact on losses," IEEE PES ISGT Europe 2013, Lyngby, 2013, pp. 1-5.

[19] B. Han, S. Lu, F. Xue, L. Jiang and X. Xu, "Three-stage electric vehicle scheduling considering stakeholders economic inconsistency and battery degradation," in IET Cyber-Physical Systems: Theory \& Applications, vol. 2, no. 3, pp. 102-110, 102017.
[20] Zhi Qiao and Jin Yang, "Electric Vehicle charging management algorithm for a UK low-voltage residential distribution network," 2016 IEEE PES Asia-Pacific Power and Energy Engineering Conference (APPEEC), Xi'an, 2016, pp. 156-160.

[21] Xydas, Erotokritos, Charalampos Marmaras, and Liana M. Cipcigan. "A multi-agent based scheduling algorithm for adaptive electric vehicles charging." Applied energy 177, pp. 354-365, 2016.

[22] "Energy Storage Capacity Set to Soar, 300 UK-Based Companies Involved in New Sector." RenewableUK, 2018. [Online]. Available: https://www.renewableuk.com/news/425522/Energy-storage-capacityset-to-soar-300-UK-based-companies-involved-in-new-sector.htm

[23] J. L. Lorente, X. A. Liu, R. Best and D. J. Morrow, "Energy storage allocation in power networks - A state-of-the-art review," 2018 53rd International Universities Power Engineering Conference (UPEC), Glasgow, 2018, pp. 1-6.

[24] M. Ross, C. Abbey, F. Bouffard and G. Joós, "Microgrid Economic Dispatch With Energy Storage Systems," in IEEE Transactions on Smart Grid, vol. 9, no. 4, pp. 3039-3047, July 2018.

[25] K. Chaudhari, A. Ukil, K. N. Kumar, U. Manandhar and S. K. Kollimalla, "Hybrid Optimization for Economic Deployment of ESS in PV-Integrated EV Charging Stations," in IEEE Transactions on Industrial Informatics, vol. 14, no. 1, pp. 106-116, Jan. 2018

[26] Department for Business, Energy \& Industrial Strategy, "Renewable electricity capacity and generation (ET 6.1)", January 2019. [Online]. Available: https://www.gov.uk/government/statistics/energy-trendssection-6-renewables.

[27] EirGrid, SONI, "All - island wind and fuel mix report", 2018. [Online]. Available: http://www.eirgridgroup.com/sitefiles/library/EirGrid/Generation_Capaci ty_Statement_2018.pdf

[28] Government Digital Service, "Feed-in tariffs: Get money for generating your own electricity", 2019. [Online]. Available: https://www.gov.uk/feed-in-tariffs

[29] NIdirect government services, "Electric Vehicles", 2019. [Online]. Available: https://www.nidirect.gov.uk/articles/electric-vehicles

[30] Energy Networks association, "The Open Networks Project". [Online]. Available: http://www.energynetworks.org/electricity/futures/opennetworks-project

[31] EA Technology, "Development of the Transform Model for Northern Ireland", June. 2016. [Online]. Available: https://www.nienetworks.co.uk/documents/future plans/development-ofthe-transform-model-for-nie-network.aspx

[32] B. Zhou and T. Littler, "Local storage meets local demand: a technical solution to future power distribution system," in IET Generation, Transmission \& Distribution, vol. 10, no. 3, pp. 704-711, 2016.

[33] B. Zhou, T. Littler and L. Meegahapola, "Assessment of transient stability support for electric vehicle integration" 2016 IEEE Power and Energy Society General Meeting (PESGM), Boston, MA, 2016, pp. 1-5.

[34] J. Foster, X. Liu and S. McLoone, "Short-term load forecasting with high levels of distributed renewable generation," 2017 52nd International Universities Power Engineering Conference (UPEC), Heraklion, 2017, pp. 1-6.

[35] Mondol, J. D., Yohanis, Y., Smyth, M., and Norton, B. "Long term performance analysis of a grid connected photovoltaic system in Northern Ireland." Energy Conversion and Management, vol. 47, issues 18-19, pp. 2925-2947, 2006.

[36] M. Martin Almenta, D. J. Morrow, R. J. Best, B. Fox and A. M. Foley, "An Analysis of Wind Curtailment and Constraint at a Nodal Level," in IEEE Transactions on Sustainable Energy, vol. 8, no. 2, pp. 488-495, April 2017.

[37] E. McKenna, P. Grünewald and M. Thomson, "Going with the wind: temporal characteristics of potential wind curtailment in Ireland in 2020 and opportunities for demand response," in IET Renewable Power Generation, vol. 9, no. 1, pp. 66-77, 12015.

[38] UN General Assembly Transforming our world: the 2030 agenda for sustainable development. United Nations, New York; 2015. [Online]. Available: https://www.un.org/ga/search/view_doc.asp?symbol=A/RES/70/1\&Lang=E

[39] Office of Gas and Electricity Markets (Ofgem), "Low Carbon Networks Fund Governance Document," 2013. [Online]. Available: https://www.ofgem.gov.uk/electricity/distribution-networks/networkinnovation/low-carbon-networks-fund.

[40] P. Palensky and D. Dietrich, "Demand Side Management: Demand Response, Intelligent Energy Systems, and Smart Loads," in IEEE Transactions on Industrial Informatics, vol. 7, no. 3, pp. 381-388, Aug. 2011. 